Proc $2^{\text {nd }}$ APCRS

\title{
Degradation trend of coral reefs in the coastal waters of Vietnam
}

\author{
Nguyen Van LONG ${ }^{1, *}$ and Tuan Si Vo ${ }^{1}$ \\ ${ }^{1}$ Institute of Oceanography, 01 Cau Da, Nha Trang, Khanh Hoa, Vietnam \\ * Corresponding author: N. V. Long \\ E-mail: longhdh@gmail.com
}

\begin{abstract}
Monitoring of coral reefs in Vietnam have been conducted at 42 permanent sites in seven key areas in the coastal waters of Vietnam, including $\mathrm{Cu}$ Lao Cham, Van Phong Bay, Nha Trang Bay, Ninh Hai - Ninh Thuan, Ca Na Bay, Con Dao and Phu Quoc, using SCUBA diving. The numbers of reefs in excellent and good conditions decreased from $7.4 \%$ and $33.3 \%$ in the period of $1994-$ 1997 to $2.9 \%$ and $11.6 \%$ in the period of 2004-2007 respectively. The number of coral reefs in bad and very bad conditions increased from $14.8 \%$ (1994-1997) to $50.0 \%$ (2004-2007). The percentage of coral reefs in fair condition remained relatively stable, averaging 44.5\% (1994$1997)$ to $40.6 \%$ (2004-2007). The quality of most coral reefs has been significantly decreasing between 19942007, with annual degradation rate averaging $1.14 \%$ for live corals, $0.93 \%$ for hard corals and $0.27 \%$ for soft corals. Total density of fish significantly increased over time, with mainly increasing density of small fish at size class of $1-10 \mathrm{~cm}$. Density of large fish $(>20 \mathrm{~cm})$, mainly target and predatory fish decreased over time. The target indicators of macro-invertebrates are extremely rare with the exception of sea urchins and crown of thorn starfish. Density of top shells, edible sea cucumbers and crown of thorn starfish slightly increased while giant clams and sea urchins significantly decreased over time. Ratio of reefs with active outbreak of crown of thorn starfish in the central of Vietnam increased from $0 \%$ in 1998 to $45.5 \%$ in 2002 and $35.7 \%$ in 2007 . This indicates that coral reefs in the coastal waters of Vietnam are not in good condition and have been degrading over time.
\end{abstract}

Keywords Coral reefs, Monitoring, Degradation, Vietnam

\section{Introduction}

Coral reefs are important habitats in the coastal waters of Vietnam, playing important roles as reservoirs of biodiversity, for fisheries and tourist development in the coastal zone. Recent studies indicated that coral reefs in many areas of Vietnam are deteriorating as a result of various natural and anthropogenic impacts such as overfishing, destructive fishing, eutrophication, sedimentation, reef mining, dredging, tourism, hurricanes, coral bleaching, coral diseases and outbreak of coral-eating predators (Tuan et al. 2005). Management activities have been recently imple-mented to address these impacts in some areas. As part of the management process, reef monitoring is being used as the primary tool for understanding changes of coral reef communities under natural and anthropogenic impacts and for providing appropriate recommendations for coral reef management.

\section{Materials and methods}

Monitoring studies were conducted from 1994-2007 in seven key areas in the coastal waters of Vietnam within the framework of different projects (Fig. 1). The numbers of monitoring sites established at each area were 5 sites at 


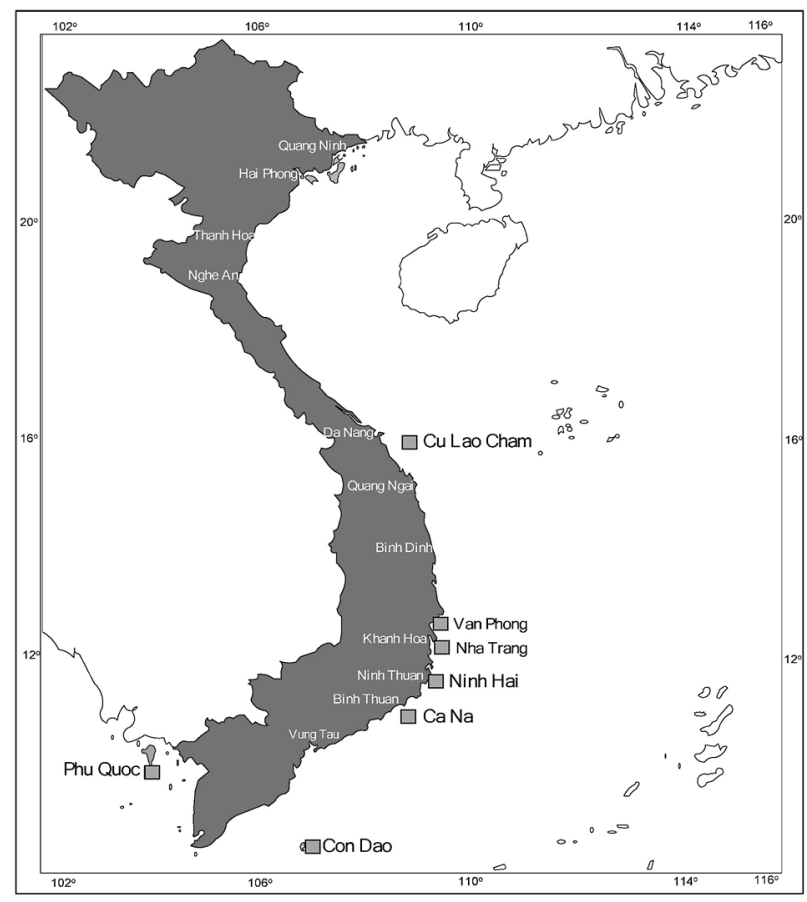

Fig. 1 Approximate locations $(\square)$ of monitoring areas in the coastal waters of Vietnam.

$\mathrm{Cu}$ Lao Cham, 4 sites at Van Phong Bay, 8 sites at Nha Trang Bay, 6 sites at Ninh Hai, 5 sites at $\mathrm{Ca} \mathrm{Na}$ Bay, 8 sites at Con Dao and 6 sites at Phu Quoc, giving a total of 42 sites.

Visual quantitative assessments of coral reefs were conducted at 2 depths (reef flat: 2-4 m and reef slope: 5-12 m) in the 42 monitoring sites. Cover of hard corals, soft corals, other sessile benthos, abundance and size of fishes and key macro-invertebrate indicators were assessed using standard methods based on the Reefcheck protocols (Hodgson and Waddell, 1997) with some additional indicators of fish families following English et al. (1997).

Data were transformed to improve normality, linearity, and homoscedasticity. To remove heterogeneity of variances, abundance of fish and invertebrates were transformed to $\log (X+1)$. Environmental variables including the percentage cover of live corals, hard corals and soft corals were transformed by arcsine of square root $(\mathrm{X})$. The variations between years in benthic cover, density of fish and invertebrates were tested using two way ANOVA. When ANOVAs detected significant differences, Tukey's post hoc test was used to compare changes in benthic cover and abundance of fish and invertebrates over the

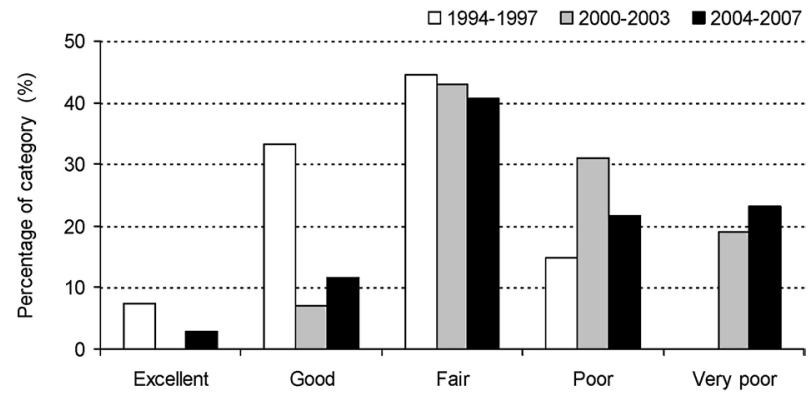

Fig. 2 Changes in percentages of coral reefs in different categories of live coral cover.

consecutive years.

\section{Results and discussion}

\section{Status and temporal changes in cover of coral reefs}

Data from the seven monitoring areas collected from 1994-2007 show that coral reefs in coastal waters of Vietnam were not in good condition and have been degrading over time (Fig. 2). The numbers of coral reefs in excellent and good conditions decreased from $7.4 \%$ and $33.3 \%$ in $1994-1997$ to $2.9 \%$ and $11.6 \%$ in 2004-2007 respectively. The number of coral reefs in bad and very bad conditions increased from $14.8 \%$ in $1994-1997$ to $50.0 \%$ in $2004-$ 2007. The percentage of coral reefs in fair condition remained relatively stable, averaging $44.5 \%$ in the period of 1994-1997 to $40.6 \%$ in the period of 2004-2007.

The quality of most coral reefs has been significantly decreasing, with degradation rate in the period of 19942007 ranging between $2.8-29.7 \%(p<0.001$; average: $10.6 \%)$ for live coral cover, $2.7-16.8 \%(p<0.05$; average: $8.3 \%)$ for hard coral cover and $0.1-12.9 \%(p<0.01$; average: $2.8 \%$ ) for soft coral cover (Fig. 3 and Table 1).

Of all areas, Con Dao had the highest degradation rate (2.97\% of live coral cover per year), followed by Ninh Hai-Ninh Thuan $(1.26 \%$ per year) and Nha Trang Bay (1.25\% per year), while loss of cover was $<1 \%$ per year for $\mathrm{Cu}$ Lao Cham, Van Phong Bay, Ca Na Bay and Phu Quoc. The notable decline in live coral cover recorded in Con Dao was caused by heavy impacts from Typhoon Linda (1997) and coral bleaching event from an increase of sea surface temperature in 1998 (Tuan 2000a). For Nha 


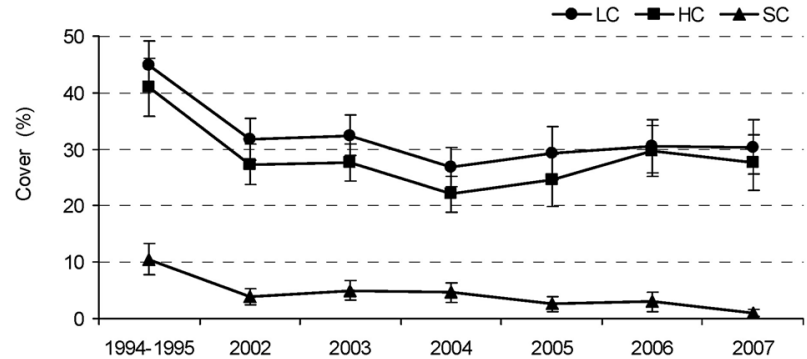

Fig. 3 Changes in cover of live corals (LC), hard corals (HC) and soft corals (SC).

Table 1 Temporal decline in coral cover in major coastal areas in the coastal waters of Vietnam.

\begin{tabular}{lllllll}
\hline No & Area & NS & $\begin{array}{l}\text { LC } \\
(\%)\end{array}$ & $\begin{array}{l}\text { HC } \\
(\%)\end{array}$ & $\begin{array}{l}\text { SC } \\
(\%)\end{array}$ & Interval \\
\hline 1 & $\begin{array}{l}\text { Cu Lao } \\
\text { Cham }\end{array}$ & 5 & -3.6 & -5.4 & 1.8 & $1994-2004$ \\
2 & $\begin{array}{l}\text { Van } \\
\text { Phong }\end{array}$ & 5 & -2.8 & -2.7 & -0.1 & $2003-2006$ \\
3 & $\begin{array}{l}\text { Nha } \\
\text { Trang }\end{array}$ & 8 & -16.2 & -13.1 & -3.1 & $1994-2007$ \\
4 & Ninh Hai & 6 & -6.3 & -6.5 & 0.2 & $2002-2007$ \\
5 & Ca Na & 5 & -6.3 & -4.9 & -1.4 & $1995-2006$ \\
6 & Con Dao & 8 & -29.7 & -16.8 & -12.9 & $1994-2004$ \\
7 & Phu & 6 & -9.0 & -8.9 & -0.1 & $1994-2007$ \\
& Quoc & & & & & \\
\hline
\end{tabular}

Remarks: NS $=$ Number of sample sites $\mathrm{LC}=$ decline in live coral cover, $\mathrm{HC}=$ Decline in hard coral cover, $\mathrm{SC}=$ Decline in soft coral cover

Trang Bay, degradation of coral reefs has been caused by increase in sediments, outbreak of crow-of-thorns starfish (COTS) and tourism (Tuan et al. 2004, 2005), especially for the coral reefs close to the mainland (Nguyen and Phan, 2008).

\section{Status and temporal changes of coral reef fishes}

Density of total fish and small fish at size class of $1-10 \mathrm{~cm}$ significantly increased over time $(p<0.001)$ (Fig. $4)$. There was a slight change over time in density of fish at size class of $11-20 \mathrm{~cm}(p>0.05)$ (Fig. 4). Average density of larger fish significantly decreased over time ( $p$ $<0.05$ ) (Fig. 5). Target and predator fish in all areas were generally recorded at very low density and changed slightly during all monitoring years $(p>0.05)$. A large variation and an increase in density were found for both butterflyfish

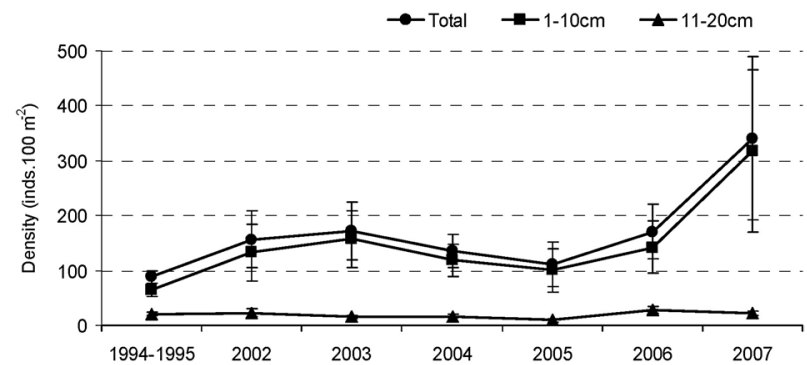

Fig. 4 Temporal changes in mean density of total fish and fish at size classes of $1-10 \mathrm{~cm}$ and $11-20 \mathrm{~cm}$.

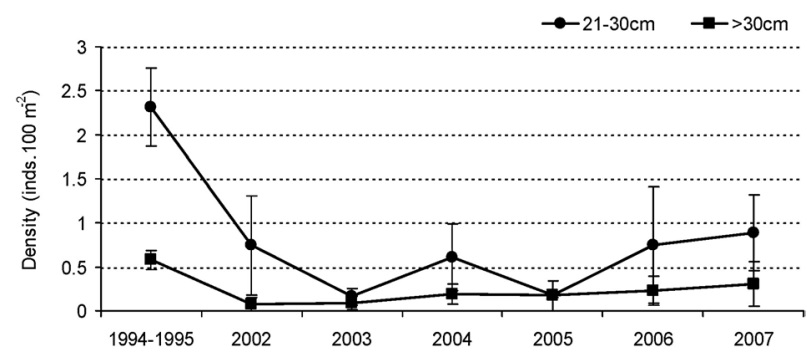

Fig. 5 Temporal changes in mean density of fish at size class of $21-30 \mathrm{~cm}$ and $>30 \mathrm{~cm}$.

$(p<0.01)$ and groupers $(p>0.05)$. Density of butterflyfish and groupers showed that there was a slight change in all monitoring areas with the exception of a notable increase of butterflyfish in Phu Quoc, and of groupers in Nha Trang Bay and Phu Quoc. A notable decline in density in Con Dao was caused by decrease in coral cover under impacts from Typhoon Linda (1997) and bleaching event in 1998 (Tuan 2000b) because species richness and abundance of coral reef fish are positively correlated with cover of living hard corals (Carpenter et al. 1981; Bell and Galzin, 1984; Cadoret et al. 1999; Nguyen and Phan, 2008).

\section{Status and temporal change of macro-invertebrate in- dicators}

Target indicators of macro-invertebrates are extremely rare with the exception of sea urchins (Diadema spp.) and crown-of-thorn starfish (COTS: Acanthaster planci). There was a significant decrease in density of giant clams (Tridacna spp.) $(p<0.001)$ and sea urchins (Diadema spp.) $(p<0.05)$ over time (Fig. 6). Density of sea cucumbers was extremely low in all monitoring areas over time (averaging $<0.5$ individual $/ 100 \mathrm{~m}^{2}$ ) and this increased 


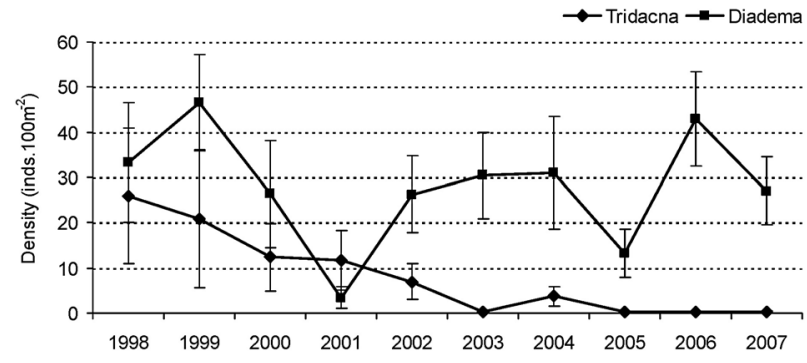

Fig. 6 Temporal changes in mean density of giant clams and sea urchins.

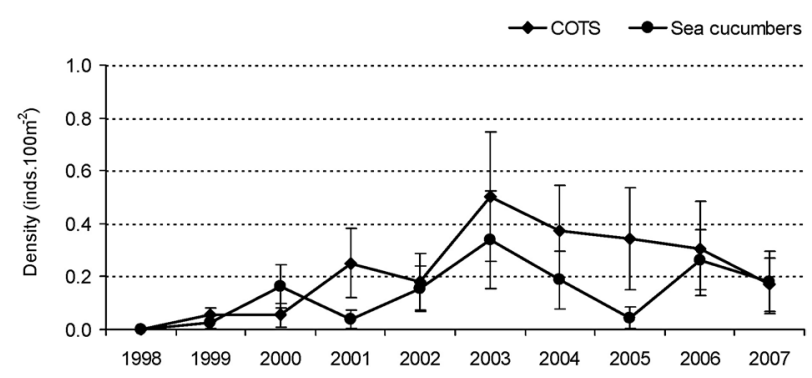

Fig. 7 Temporal changes in mean density of crown-ofthorn starfish (COTS) and sea cucumbers.

slightly between years $(p>0.05)$ (Fig. 7). Density of top shells (Trochus spp.) was very low and increased slightly over time. Lobsters (Panulirus spp.) and banded coral shrimp (Stenopus hispidus) were extremely rare over time, with average density being $<0.2$ individuals $/ 100 \mathrm{~m}^{2}$ and this increased from 2001-2005 for lobster (0.0-0.14 individuals $\left./ 100 \mathrm{~m}^{2}\right)$ and for banded coral shrimp (0.020.18 individuals $/ 100 \mathrm{~m}^{2}$ ). However, the increase was not significant $(p>0.05)$. Some other Reefcheck indicators such as triton shell (Charonia tritonis) and pencil urchin (Heterocentrotus mammilatus) were absent in all monitoring areas over time.

Density of COTS increased in the period of 2000-2004 and gradually decreased from 2005-2007 ( $p>0.05$ ) (Fig. $7)$, with a higher density being recorded in Van Phong Bay, Nha Trang Bay and $\mathrm{Cu}$ Lao Cham. Ratio of reefs with active outbreak increased from $0 \%$ in 1998 to $45.5 \%$ in 2002 and $35.7 \%$ in 2007; and number of reefs with no recent break of COTS decreased from $100 \%$ in 1998 to $64.3 \%$ in 2007 (Fig. 8). The increase in density of COTS from 2000-2004 may be related to the outbreak of COST occurred during this period, while the decrease may be

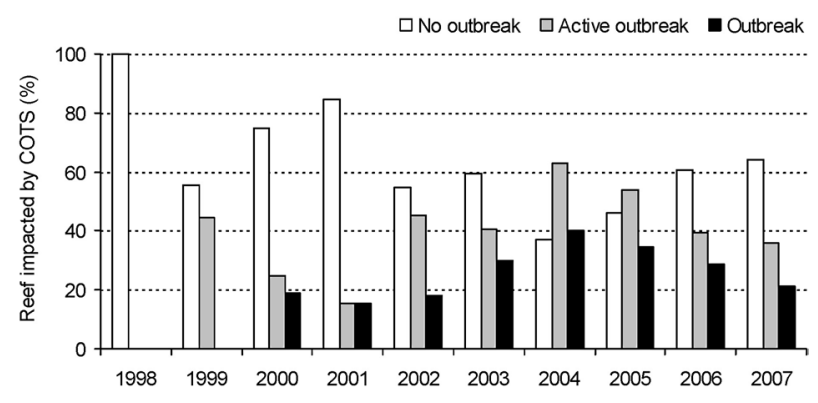

Fig. 8 Temporal changes in percentage of coral reefs at different levels of infection by COTS with No Recent Outbreak, Active Outbreak and Outbreak.

coincided with the decline of the outbreak because the outbreak of COTS usually last about 4-5 years (Moran 1988). These finding were similar to those found in the Great Barrier Reef in Australia (Sweatman et al. 2005).

\section{Conclusions}

Coral reefs in the coastal waters of Vietnam were generally not in good condition and the quality of most coral reefs has been significantly decreasing in the period of 1994-2007. Many of reefs in the central of Vietnam have been affected by COTS in recent years with the ratio of reefs with active outbreak of COTS increasing over time. Small fishes $(<10 \mathrm{~cm}$ in length), sea urchins and inedible sea cucumbers were major resources remained in coral reefs whereas target fish and macro-invertebrates were overfished and significantly decreased over time.

\section{Acknowledgements}

We gratefully acknowledge relevant organizations and agencies such as the Vietnamese Academy of Science and Technology (VAST), WWF, IUCN, DANIDA, UNEP, Total Foundation, Department of Science and Technology of Ninh Thuan Province, Nui Chua National Park, Con Dao National Park, Nha Trang Bay Marine Protected Area Authority, Cu Lao Cham Marine Protected Area Authority, Management Board of Phu Quoc UNEP/GEF/SCS Demonstration Site of Coral Reefs and Seagrass Beds, Phu Quoc Marine Protected Area Authority for their financial 
support and co-operation. We also thank the National Foundation for Science and Technology Development (NAFOSTED, Project: 106.14-2010.67) for supporting us in gathering and synthesizing data for this publication.

\section{References}

Bell JD, Galzin R (1984) Influence of live coral cover on coral reef fish communities. Mar Ecol Prog Ser 15: 265-274

Cadoret L, Adjeroud M, Tsuchiya M (1999) Spatial distribution of chaetodontid fish in coral reefs of the Ryukyu Islands, southern Japan. J Mar Biol Assoc UK 79: 725-735

Carpenter KE, Miclat RI, Albaladejo VD, Corpuz VT (1981) The influence of substrate structure on the local abundance and diversity of Philippine reef fishes. Proc 5th Int Coral Reef Symp 2: 497-502

English S, Wilkinson C, Baker V (1997) Survey manual for tropical marine resource. $2^{\text {nd }}$ Edition. Australian Institute of Marine Sciences, Townsville, p 390

Hodgson G, Waddell S (1997) international reef check core method. University of California at Los Angeles.

Moran PJ (1997) Crown-of-thorns starfish - Questions and answers. Australian Institute of Marine Sciences, Townsville,

\section{p. 35}

Nguyen VL, Phan KH (2008) Distribution and factors influencing on structure of reef fish communities in Nha Trang Bay Marine Protected Area, South-Central Vietnam. Environ Biol Fishes 82: 309-324

Tuan VS (2000a) Report on status of coral reefs in Vietnam. Proc 9th Int Coral Reef Symp 2: 891-894

Tuan VS (2000b) The orals at Condao Archipelago (South Vietnam): Before, during and after the bleaching event in 1998. Proc 9th Int Coral Reef Symp 2: 895-899

Tuan VS, Long NV, Hoang PK, Ben HX, Tuyen HT (2004) Community-based monitoring in Hon Mun Marine Protected Area. Unpublished Report, p 77

Tuan VS, Nguyen Huy Yet, Nguyen Van Long (2005) Coral reefs of Vietnam. Publishing House of Science and Technology, p. 212 (in Vietnamese).

Sweatman H, Burgess S, Cheal A, Coleman G, Delean S, Emslie M, McDonald A, Miller I, Osborne K, Thompson A (2005) Long-term monitoring of the Great Barrier Reef - Status report number 7. Australian Institute of Marine Sciences, Townsville, p. 257

(C) Japanese Coral Reef Society 